\title{
On the Role of Chloroplasts in the Polymerization of Tannins in Tracheophyta: A Monograph
}

\author{
Jean-Marc Brillouet \\ UMR SPO INRA/SupAgro/UM I, Montpellier, France \\ Email: brilloue@supagro.inra.fr
}

Received 26 January 2015; accepted 12 June 2015; published 15 June 2015

Copyright (c) 2015 by author and Scientific Research Publishing Inc.

This work is licensed under the Creative Commons Attribution International License (CC BY).

http://creativecommons.org/licenses/by/4.0/

(c) (i) Open Access

\begin{abstract}
Proanthocyanidins are formed in the chlorophyllous organs of Tracheophyta from a redifferentiation of chloroplasts involving the thylakoidal membrane and lumen. With the purpose to help researchers of concerned disciplines to identify such chloroplasts, we described herein the morphologies of functional and redifferentiating chloroplasts in various members of Tracheophyta. The most obvious sign of redifferentiation is a tremendous swelling of the chloroplast which turns obese. De novo genesis of osmiophilic materials is also characteristic, either as single dots attached to the inner face of the swollen thylakoidal membrane which will yield the tannosomes, or as pearl necklace-shaped structures protruding into the lumen; this last formation can be viewed as a giant tannosome forming finally stromal chlorotannic accretions. Whatever their mode of formation is, tannosomes are expulsed from the chloroplast as shuttles.
\end{abstract}

\section{Keywords}

Condensed Tannins, Proanthocyanidins, Thylakoids, Tannosome, Plastid, Tracheophyta

\section{Introduction}

Proanthocyanidins (also called condensed tannins) are, after lignin, the major phenolics in plant kingdom. They are oligo- and polymers of flavan-3-ols (mainly epicatechin and epigallocatechin) linked through C4 $\rightarrow$ C8 and $\mathrm{C} 4 \rightarrow$ C6 linkages and bearing various proportions of galloyl esters on C3. They provide defense against herbivores and pathogens, and protection against UV radiation. We recently demonstrated that polymerization of building blocks (the catechins) occurs, inside the chlorophyllous organs of Tracheophyta, in a new chloroplastderived organelle, the tannosome [1]. Later, we described the agglomeration of tannosome-containing shuttles 
into superstructures, the chlorotannic accretions [2]; finally, various modes of tannosome ontogenesis were depicted [3].

With the aim to provide detailed morphological data concerning scientific community which will, in the future, enable researchers to identify them, we present a monograph of large-size micrographs of photosynthetic chloroplasts from the Tracheophyta and their counterparts, the redifferentiating chloroplasts producing tannins.

\section{Methods and Methods}

\subsection{Plant Materials}

Leaflets fromfern (Dryopteris sp., Pteridophyta), horsetail (Equisetum arvense, Equisetophyta), Cycasrevoluta (Cycadophyta), Ginkgo biloba (Ginkgophyta), rubber tree (Heveabrasilensis, Magnoliophyta, Eudicots), and persimmon (Dyospiros kaki, Magnoliophyta, Eudicots), stalks from Saccharum sp. (Magnoliophyta, Monocots), scales from Cupressus macrocarpa (Coniferophyta), peduncles of Chamaeropshumilis and pistils and immature fruits from Butiacapitata (Magnoliophyta, Monocots) and grapevine (Vitisvinifera, Magnoliophyta, Eudicots) were collected in the Montpellier City botanical garden.

\subsection{Transmission Electron Microscopy}

Specimens were dipped in $50 \mathrm{mM}$ sodium cacodylate buffer (pH 7.0) containing 6\% glutaraldehyde (w/v) [4] and $1 \%$ caffeine $(\mathrm{w} / \mathrm{v})$ for $6 \mathrm{~h}$, then treated with $1 \%$ osmium tetroxide $(\mathrm{w} / \mathrm{v})$ in water for $1 \mathrm{~h}$ at room temperature. After dehydration, they were embedded in Epon Em Bed 812. Sections were stained with 0.2\% Oolong tea [5]. Ultrathin sections $(60 \mathrm{~nm})$ were visualised by an H-7100 Hitachi transmission electron microscope with $75 \mathrm{kV}$ accelerating voltage.

\section{Results}

All photosynthetic chloroplasts were ellipsoidal in shape (long axis 2 - $3 \mu \mathrm{m}$, short axis 1.5 - $2 \mu \mathrm{m}$ ) andseemed in good state of preservation with well visible outer and inner membranes, well-constitutedgrana thylakoids, and stromal lamellae (Plates 1(A)-11(A)). Apart some plastoglobules in certain species (Plate 2(A), Plate 4(A), Plates 5-7(A), Plates 9-11(A)), no osmiophilic deposits were visible. Starch granules were occasionally present and ferritin mostly visible.

Redifferentiation into tannin-generating chloroplasts showed multiple signs of loss of photosynthesis capacity. The most obvious morphological alteration was a global inflation of the chloroplast body, turning from ellipsoidal to obese and pseudospherical (Plate 1(B), Plate 1(B'), Plate 2 and Plate 3(B), Plates 6-8(B), Plate 10 and Plate 11(B)) (doubling of the length of the short axis) or pseudocylindrical (Plate 4 and Plate 5(B)). Grana dismantled by separation of the thylakoids which maintained their regular thickness $(20 \mathrm{~nm})$ on their whole

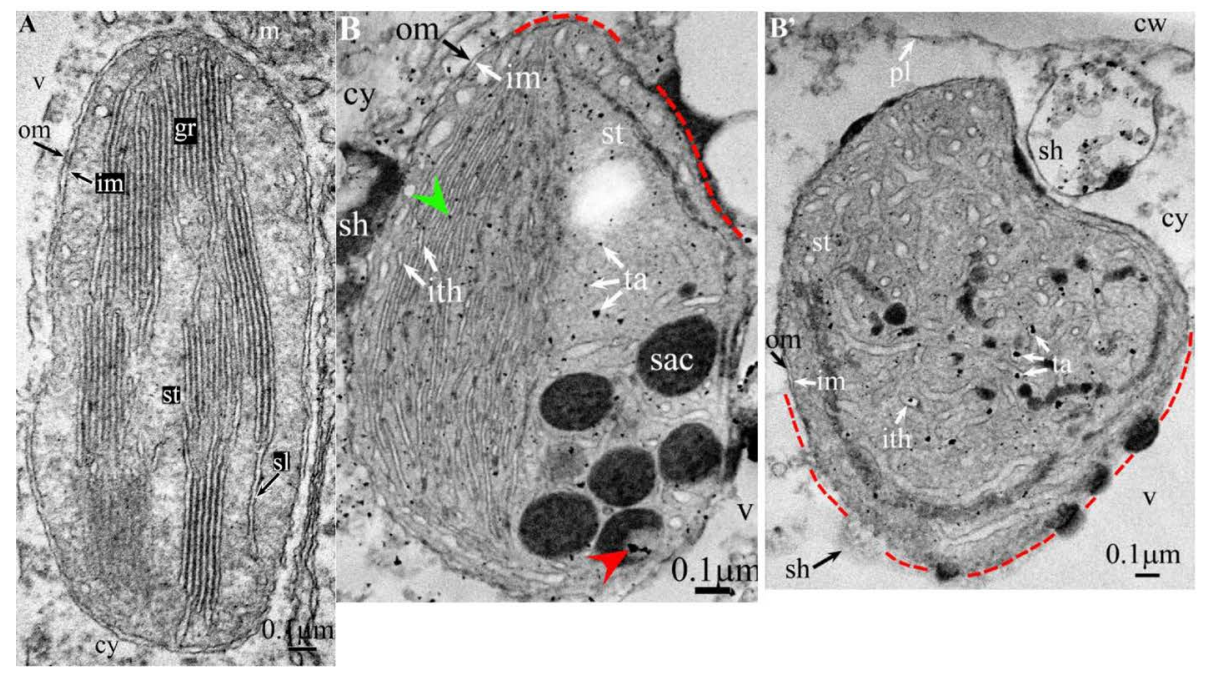

Plate 1. Vitis vinifera. 

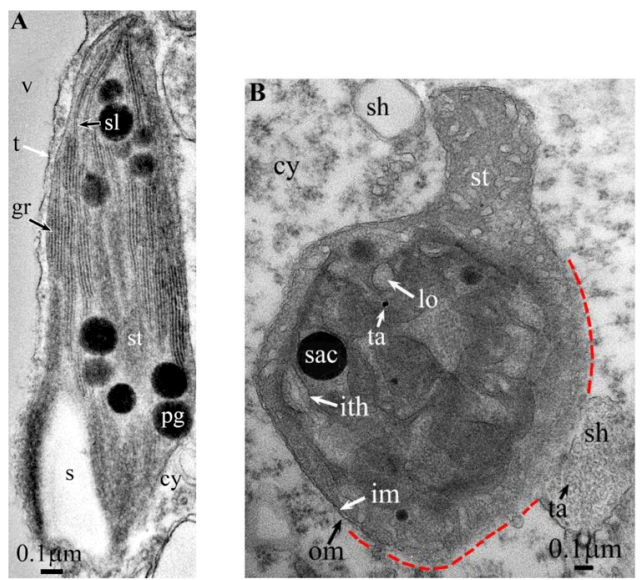

Plate 2. Dyospiros kaki.
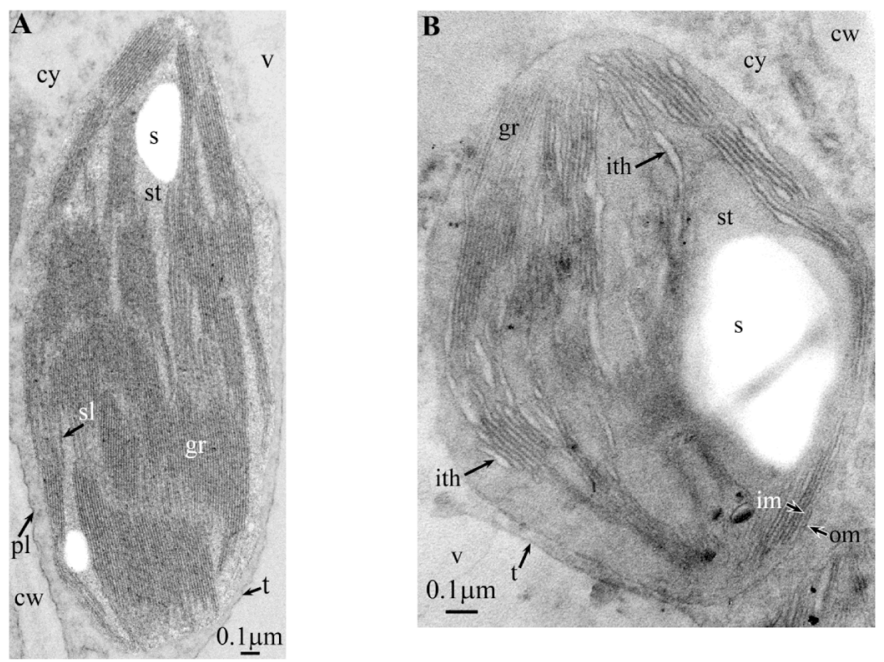

Plate 3. Hevea brasilensis.
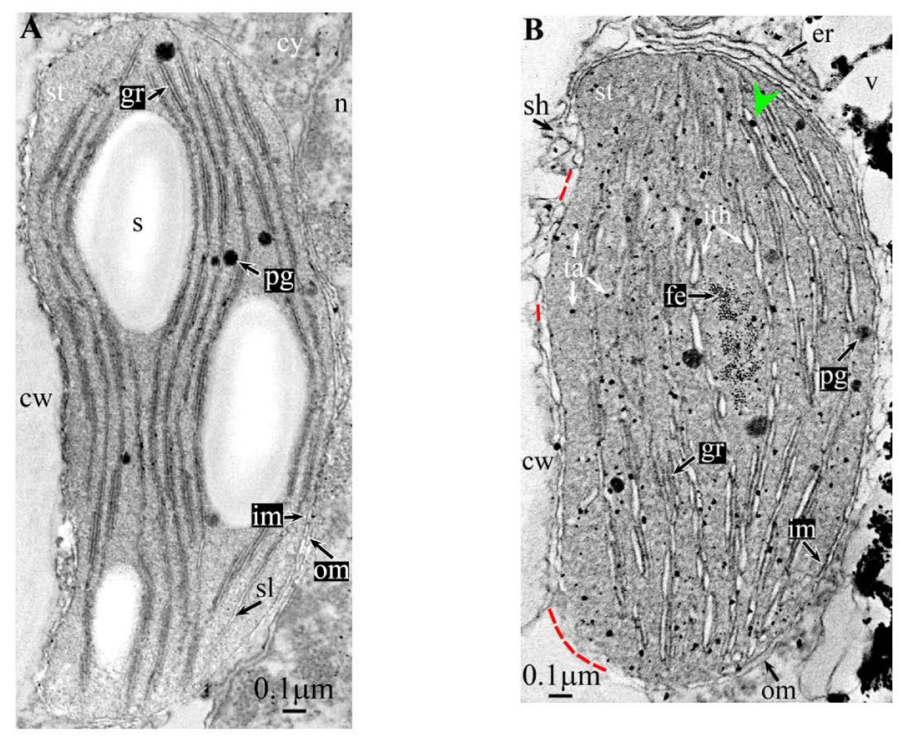

Plate 4. Cupressus macrocarpa. 

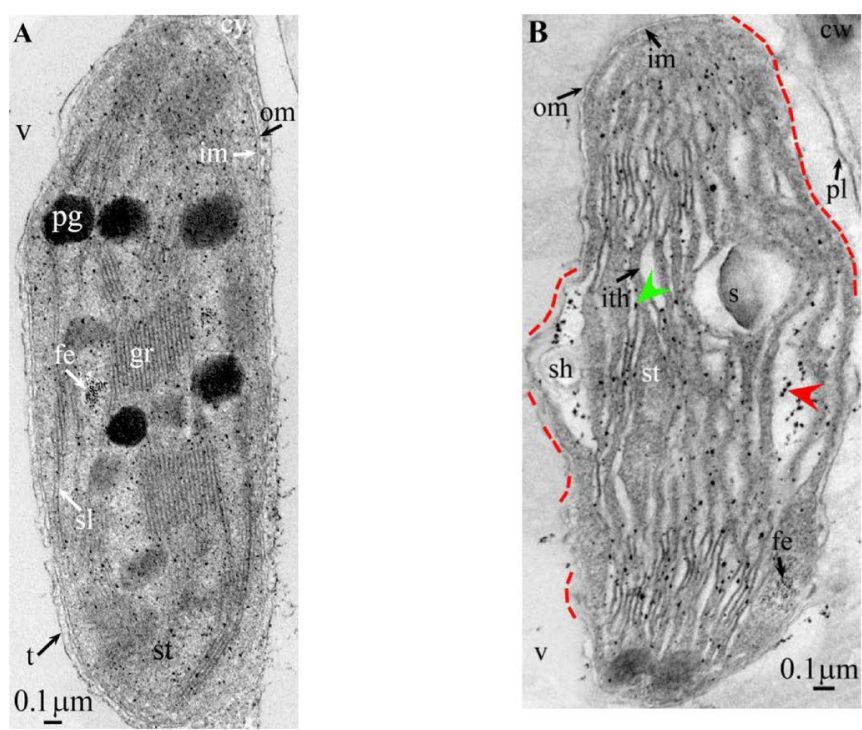

Plate 5. Saccharum.
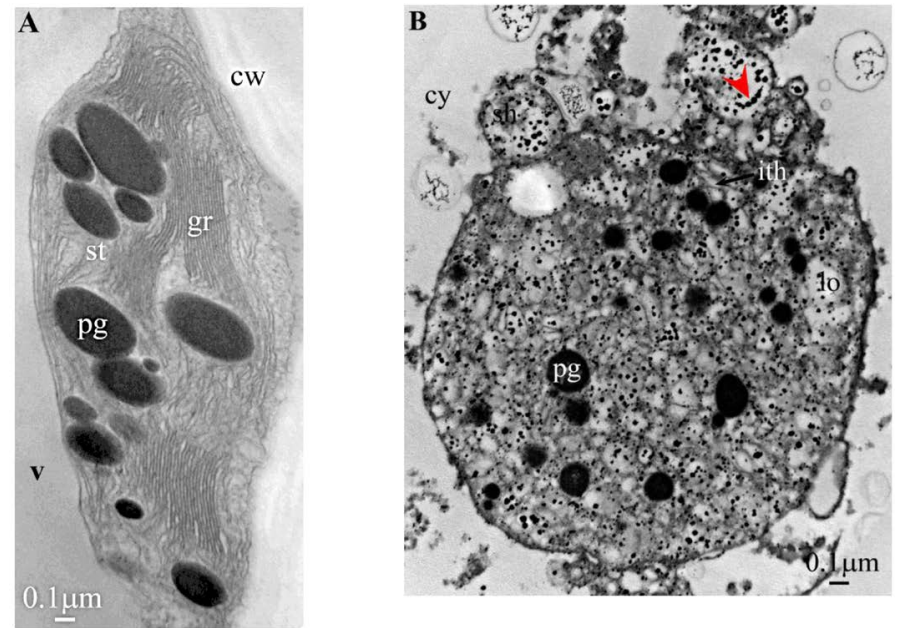

Plate 6. Butia capitata.
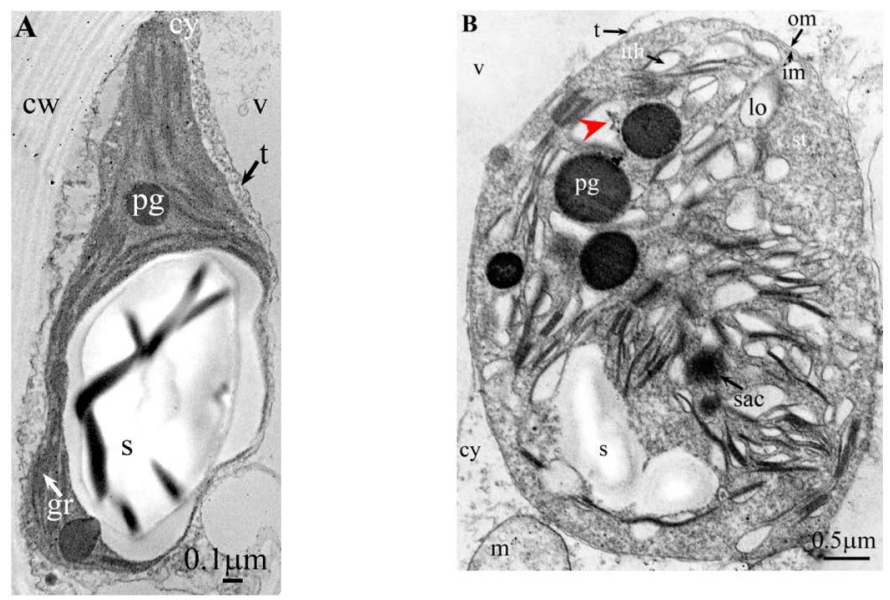

Plate 7. Chamaerops humilis. 

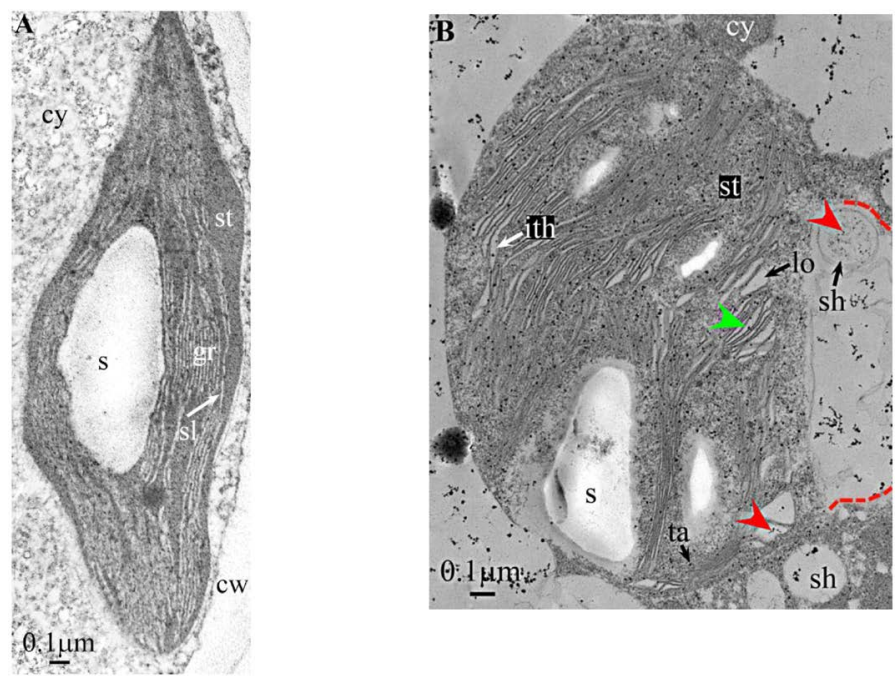

Plate 8. Dryopteris.
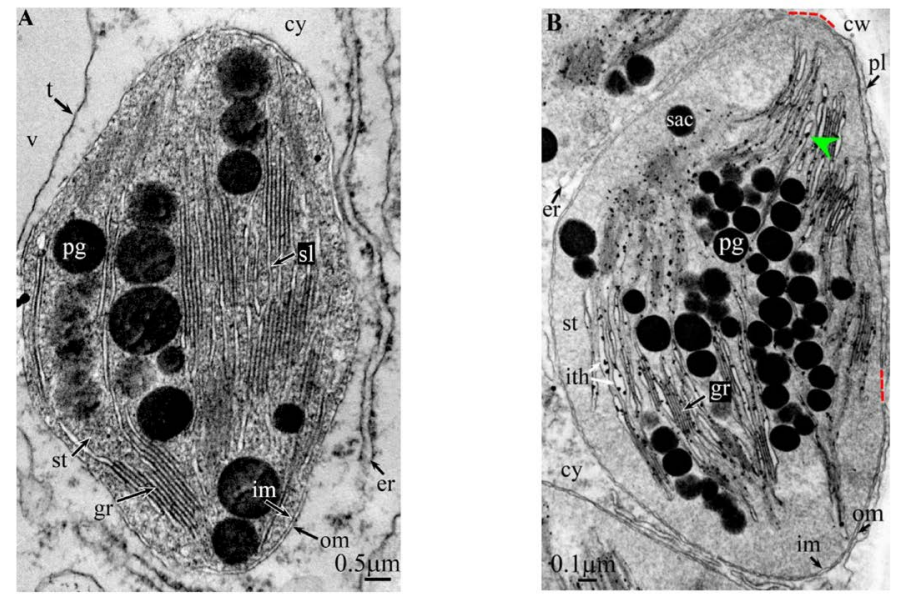

Plate 9. Cycas revoluta.
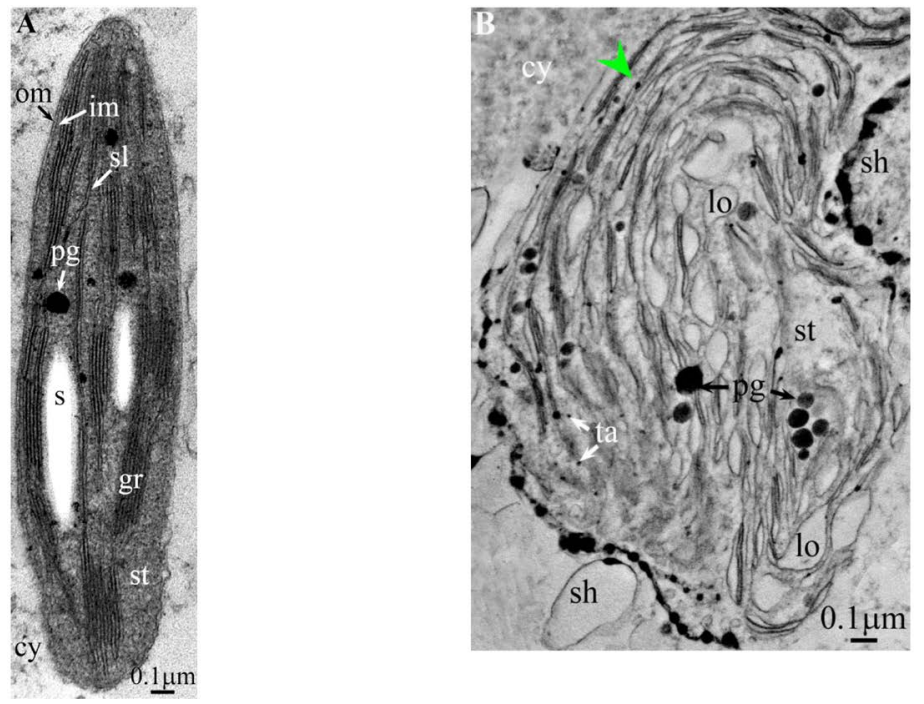

Plate 10. Equisetum arvense. 

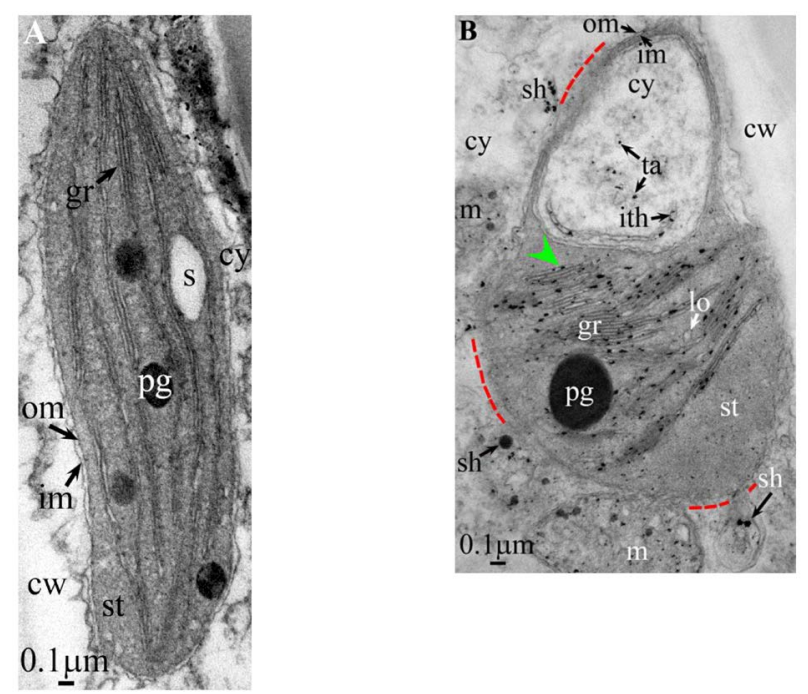

Plate 11. Ginkgo biloba.

length (Plate 1(B), Plate 9(B), Plate 11(B)), or the separation partially occured, but, on a certain length of the grana, the lumen swelled enormously generating loculiof various volumes and shapes (lens, sphere...) (Plates 5-8(B), Plate 10(B)).

Soon or simultaneously emerged in the intrathylakoidal lumen osmiophilic spheroidal dots attached to the inner face of the thylakoidal membrane while thylakoids swelled slightly (up to $30 \mathrm{~nm}$ thickness) (marked with a green arrowhead in Plate 1(B), Plate 4 and Plate 5(B), Plates 8-11(B)). When loculi were formed, deposition of osmiophilic material occurred differently from above: spheroidal dots, linked in a pearl-necklace structure, appeared and extended into the locule lumen from a unique site of attachment to the inner face of the thylakoidal membrane (marked with a red arrowhead in Plates 5(B)-8(B)). It seems that both modes can co-existin the same chloroplast (Plate 5(B)). In all cases, were also seen highly swollen "sterile” thylakoids, i.e. bearing no osmiophilic dots (Plate $\mathbf{1}\left(\mathbf{B}^{\prime}\right)$ and Plate $2(\mathbf{B})$ ).

Another typical alteration laid in the two peripheral membranes: while they were well visible at the whole periphery of functional chloroplasts, they were no longer visible in variable portions of the periphery of redifferentiating chloroplasts, and still well visible in the rest of the periphery; when no visible, they were replaced by a diffuse fluffy cotton-like zone (marked with a red dotted line in Plate 1(B), Plate 1(B'), Plate 2(B), Plate 4, Plate 5(B), Plate 8(B), Plate 11(B)).

In some cases, shuttles carrying isolated tannosomes or fragments of swollen thylakoids were well visible (Plate 1(B'), Plate 2(B), Plate 6(B), Plate 8(B), Plate 11(B)).

\section{Discussion}

Firstly, amongst a population of chloroplasts of a given species, only an unknown portion of them undergoes redifferentiation into tannin-producing organelles. Examination of about ten thousands of micrographs did not allow to measure these proportions since a statistical analysis would have required viewing a much greater number of micrographs, i.e. several tenths of thousands; indeed, even in chlorophyllous organs where the polymerization of tannins is very active, i.e. in certain very young immature plant parts, detection of redifferentiating chloroplasts relies more on chance than on a rationale search. However, according to our experience, this proportion must be quite low ( $<10 \%$ of a population).

Secondly, it is not known if these peculiar chloroplasts exist in specialized tanniferous cells and/or in other more common cells, if they co-exist with photosynthetic chloroplasts in the same cells (not observed, but possible). We made preliminary observations indicating that their expulsed chlorotannic accretions can co-exist in the cytosol/vacuole of the same cells with other phenolics-containing particles (data not shown), e.g. anthocyanins [6].

Given this load of uncertainty, these redifferentiating chloroplasts share, in the plant kingdom, but Bryophytes and Algae, several characters with regards to their morphology (Table 1) and their modes of tannins production. 
Table 1. Morphology of photosynthetic and redifferentiating tannin-producing chloroplasts.

\begin{tabular}{|c|c|c|c|c|c|c|c|c|c|}
\hline \multirow{2}{*}{ Chloroplast } & \multicolumn{9}{|c|}{ Morphological Traits } \\
\hline & Size & Aspect & Granum & Tannosomes & Loculi & $\begin{array}{c}\text { Peripheral } \\
\text { Membranes }\end{array}$ & Shuttles & $\begin{array}{c}\text { Stromal } \\
\text { Accretions }\end{array}$ & Starch \\
\hline Photosynthetic & $\begin{array}{c}1.5-2 \mu \mathrm{m} \\
2-3 \mu \mathrm{m}\end{array}$ & $\begin{array}{c}\text { Mostly } \\
\text { ellipsoïdal, } \\
\text { streched }\end{array}$ & Yes & No & No & Visible & No & No & $\begin{array}{c}\text { Generally } \\
\text { yes }\end{array}$ \\
\hline Redifferentiating & $\begin{array}{c}3 \mu \mathrm{m} \\
2-3 \mu \mathrm{m}\end{array}$ & $\begin{array}{c}\text { Inflated, } \\
\text { bulbous, } \\
\text { pseudospherical, } \\
\text { or vaguely } \\
\text { cylindrical }\end{array}$ & $\begin{array}{c}\text { Mostly no/ } \\
\text { Rarely yes } \\
\text { Unstacked } \\
\text { inflated } \\
\text { thylakoids }\end{array}$ & Yes & Yes & $\begin{array}{l}\text { Indistinct, } \\
\text { fluffy, } \\
\text { cotton-like }\end{array}$ & Yes & Yes & $\begin{array}{c}\text { Generally } \\
\text { no }\end{array}$ \\
\hline
\end{tabular}

They can be easily distinguished from photosynthetic chloroplasts. The morphology of functional chloroplasts has been extensively described in the past (for review see [7]); their main characteristics are: presence of a multilamellar system with grana interspersed with stromal lamellae, two well-visible surrounding membranes, and absence, but plastoglobules, of osmiophilic stromal spheroidal structures and dots within ththylakoids. Their redifferentiation into plastids producing tannin-containing organelles is characteristic and different from the conversion (chloroplast $\rightarrow$ chromoplast) [8].

The formation of single tannosomes from unstacked grana (here and in [1]), the building of stromal accretions from whirling thylakoids, and the creation of pearl necklace-shaped structures in loculi (here and in [3]) seem to co-exist in most redifferentiating chloroplasts; at this stage, it is worth to note that the unstacking of grana would not be a fundamental prerequisite for the emergence in the thylakoidal lumen of osmiophilic dots (Plate 9(B) and Plate 11(B)). The significance of "sterile" thylakoids much more swollen than tannosome-generating ones remains misunderstood (Plate $\mathbf{1}(\mathrm{B}$ ') and Plate 2(B)).

If, the overall morphology of redifferentiating chloroplasts is easily recognizable, this is not the case of those from Dyospirosleaflet (Plate 2(B)): indeed, the loculi appear as rather indistinct large flower petals with no apparent osmiophilic dots. However, the emergence of well-characterized shuttles confirms their nature.

It must be noted that, as anciently and repeatedly mentioned in the literature [9] [10], condensed tannins and starch seem, most of time, to exclude each other. Wardrop and Cronshaw [10] even described in Angiosperms the formation of phenolics (likely proanthocyanidins) from amyloplasts, i.e. with concommitant degradation of starch.

At this stage, one must discuss a crucial point: the osmiophilic globuli observed in functional chloroplasts can be easily identified as plastoglobules (Plate 2(A), Plates 4-6(A) and Plates 9-11(A)); indeed, these structures are attached to the thylakoidmembrane from which they are formed; even those at a distance are linked via other plastoglobules to the thylakoid [11]. This is not the case in redifferentiating chloroplasts where these plastoglobules can co-exist with stromal chlorotannic accretions formed by the whirling of the thylakoids (Plate 1(B), Plate 2(B) and Plate 9(B)) (see also the "snail" model in [3]) or by filling of loculi (see also the "pearl necklace" model in [3]); therefore, only the pseudocircularosmiophilic bodies not attached to a thylakoidal membrane were named chlorotannicstromal accretions; those clearly attached were described as plastoglobules. Moreover, the accretions, when incompletely filled, showed pear-necklace structures (Plate 1(B) and Figures 2(C)-(E), Figure 4(A) in [3]). For few species, seriedosmicated and non-osmicated sections helped to identification (Plate 6(B)). When an ambiguity remains, they were not assigned a designation.

The dilation of thylakoids with subsequent formation of loculi also seems a general trend. Such an alteration of the thylakoid ultrastructure is frequently observed in plants submitted to various stresses, e.g. seedlings of Betulapendula submitted to excess UV-B radiation [12]; indeed, it is well known that an increased synthesis of phenolics is UV-B-inducible (e.g. vine grown at high altitude under high UV-B radiation [13]). Such dilations were also observed in vanilla chloroplasts forming 4-O-(3-methoxybenzaldehyde) glucoside [14].

Of utmost importance with regards to the existence of stromal phenolic accretions [3] and subsequent formation of shuttles [1], is the paper of Gifford and Stewart [15]: indeed, these authors described in details proplastid inclusions (PV's) in the meristematic cells of the shoot apices of Bryophyllum and Kalanchoë. These spheroïdal PV's were seen in both proplastid body and vacuole, either electron-opaque or translucent (Figure 11); authors stated that these PV's are greater than and do not resemble osmiophilic plastoglobules. In most PV's were found 
pearl necklace-shaped osmiophilic structures similar to those mentioned in Brillouet [3]. Sometimes, a faintly contrasted PV co-exists with an osmiophilic vaguely circular structure ([15]; Figure 3, Figure 5, Figure 24, Figure 25) showing an indistinct fluffy periphery; authors identified it as phytoferritin which, according to our observations, is visible as a gathering of minute individual black dots (Plate 4(B), Plate 5(A), Plate 5(B) and Figure 4(B)) in [1]). We think that these structures were more likely stromal chlorotannic accretions (Plate 1, Plate 2(B) and Plate 9(B)), and "snail" and "pearl necklace" models in [3]). Moreover tubular lamellae mentioned by Gifford and Stewart [15] (Figure 28) ressemble fragments of swollen thylakoids waiting to be packed in a budding shuttle (see Figure 5(B) and Figure 5(C)) and Figure S3(A), Figure S3(I) and Figure S3(L) [supplementary data] in [1]). Thus, it is possible that condensed tannins could be formed in non-photosynthetic proplastids with their rudimentary lamellar system. Authors showed a cell from pith rib meristem of Bryophyllum treated with glutaraldehyde, then Tollen's reagent (Figure 31): two silver deposits of similar appearance were observed in a proplastid and vacuole; they considered the possibility that these PV's contain at least small amounts of phenolic compounds which is consistent with our "snail" and "pearl necklace" models of tannin deposition in the chloroplast [3].

\section{Conclusion}

We do confirm previously published data [1]-[3] on the crucial role of the chloroplast, and possible proplastids, in the polymerization of condensed tannins. Observations reveal a great plasticity in the formation of tanninforming structures: formation of single tannosomes from the thylakoids and its variants, i.e. the "pearl necklace" and "snail" models. In all cases, these structures are expulsed out of the chloroplast and conveyed inside shuttles to the vacuole where the latter agglomerates into chlorotannic accretions [3].

\section{Acknowledgements}

The author gratefully acknowledges the contributions from Dr Chantal Cazevieille and Cécile Sanchez [Centre de Ressources en Imagerie Cellulaire (CRIC), Université Montpellier I, Montpellier, France], for their technical assistance in transmission electron microscopy. The authors declare that no conflict of interest exists with the results and conclusions presented in this paper. Publication ethics have been observed.

\section{Plates}

All illustrations are presented as two plates per species except Vitisvinifera: (A) a typical photosynthetic chloroplast; (B) a typical tannin-producing redifferentiating chloroplast; Vitis (B') additional plate showing a tannin-producing redifferentiating chloroplast with interlaced thylakoids. Abbreviations common to plates: $c w$ cell wall; cy cytoplasm; er endoplasmic reticulum; fe ferritin; gr granum; im inner membrane; ith inflated thylakoids; $n$ nucleus; om outer membrane; $p g$ plastoglobule; $p l$ plasmalemma; $s$ starch; sac stromal accretion; $s l$ stromal lamella; ststroma; ttonoplast; tatannosome; $v$ vacuole. Osmiophilic dots attached to the inner face of the thylakoidal membrane marked with a green arrowhead; pearl-necklace linked osmiophilic spheroids bound to the inner face of the intrathylakoidal loculi marked with a red arrowhead; disappearance of the two plastidial enveloping membranes marked with a red dotted line.

\section{References}

[1] Brillouet, J.-M., Romieu, C., Schoefs, B., Solymosi, K., Cheynier, V., Fulcrand, H., Verdeil, J.-L. and Conejero, G. (2013) The Tannosome Is an Organelle Forming Condensed Tannins in the Chlorophyllous Organs of Tracheophyta. Annals of Botany, 112, 1003-1014. http://dx.doi.org/10.1093/aob/mct168

[2] Brillouet, J.-M., Romieu, C., Lartaud, M., Jublanc, E., Torregrosa, L. and Cazevieille, C. (2014) Formation of Vacuolar Tannin Deposits in the Chlorophyllous Organs of Tracheophyta: from Shuttles to Accretions. Protoplasma, 251, 13871393. http://dx.doi.org/10.1007/s00709-014-0640-1

[3] Brillouet, J.-M. (2014) Plasticity of the Tannosome Ontogenesis in the Tracheophyta. Journal of Plant Sciences, 2, 317-323.

[4] Sironval, C., Kirchman, R, Bronchart, R. and Michel, J.M. (1968) Sur le Freinage de l'Accumulation des Chlorophylles dans les Feuilles Primordiales de Phaseolus vulgaris L. var. Commodore à la Suite d'une Irradiation Photorestauration en Lumière Continue. Photosynthetica, 2, 57-67. 
[5] Sato, S., Adachi, A., Sasaki, Y. and Ghazizadeh, M. (2008) Oolong Tea Extract as a Substitute for Uranyl Acetate in Staining of Ultrathin Sections. Journal of Microscopy, 229, 17-20. http://dx.doi.org/10.1111/j.1365-2818.2007.01881.x

[6] Gomez, C., Conéjéro, G., Torregrosa, L., Cheynier, V., Terrier, N. and Ageorges, A. (2011) In Vivo Grapevine Anthocyanin Transport Involves Vesicle Mediated Trafficking and the Contribution of anthoMATE Transporters and GST. The Plant Journal, 67, 960-970. http://dx.doi.org/10.1111/j.1365-313X.2011.04648.x

[7] Staehelin, L.A. (2003) Chloroplast Structure: From Chlorophyll Granules to Supra-Molecular Architecture of Thylakoid Membranes. Photosynthesis Research, 76, 185-196. http://dx.doi.org/10.1023/A:1024994525586

[8] Rosso, S.W. (1968) The Ultrastructure of Chromoplast Development in Red Tomatoes. Journal of Ultrastructural Research, 25, 307-322. http://dx.doi.org/10.1016/S0022-5320(68)80076-0

[9] Juhász, G.D., Dános, B. and Rakován, N. (1970) Licht-und Elektronmikroskopische Untersuchung Gerbstoffhaltiger Zellen in den Reproduktiven Organen der Cornus-Arten. Annales Universitatis Scientiarum Budapestinensis Derolando Eotvoa Nominatae/Sectio Biologica, 12, 158-161.

[10] Wardrop, A.B. and Cronshaw, J. (1962) Formation of Phenolic Substances in the Ray Parenchyma of Angiosperms. Nature, 193, 90-92. http://dx.doi.org/10.1038/193090b0

[11] Austin II, J.R., Frost, E., Vidi, P., Kessler, F. and Staehelin, L.A. (2006) Plastoglobules Are Lipoprotein Subcompartments of the Chloroplast That Are Permanently Coupled to Thylakoid Membranes and Contain Biosynthetic Enzymes. Plant Cell, 18, 1693-1703. http://dx.doi.org/10.1105/tpc.105.039859

[12] Kostina, E., Wulff, A. and Julkunen-Tiitto, R. (2001) Growth, Structure, Stomatal Responses and Secondary Metabolites of Birch Seedlings (Betula pendula) under Elevated UV-B Radiation in the Field. Trees, 15, 483-491. http://dx.doi.org/10.1007/s00468-001-0129-3

[13] Berli, F., D’Angelo, J., Cavagnaro, B., Bottini, R., Wuilloud, R. and Silva, M.F. (2008) Phenolic Composition in Grape (Vitis vinifera L. cv. Malbec) Ripened with Different Solar UV-B Radiation Levels by Capillary Zone Electrophoresis. Journal of Agricultural and Food Chemistry, 56, 2892-2898. http://dx.doi.org/10.1021/jf073421+

[14] Brillouet, J.-M., Verdeil, J.-L., Odoux, E., Lartaud, M., Grisoni, M. and Conéjéro, G. (2014) Phenol Homeostasis Is Ensured in Vanilla Fruit by Storage under Solid Form in a New Chloroplast-Derived Organelle, the Phenyloplast. Journal of Experimental Botany, 65, 2427-2435. http://dx.doi.org/10.1093/jxb/eru126

[15] Gifford, E.M. and Stewart, K.D. (1968) Inclusions of the Proplastids and Vacuoles in the Shoot Apices of Bryophyllum and Kalanchoё. American Journal of Botany, 55, 269-279. http://dx.doi.org/10.2307/2440411 